\title{
Technical Efficiency of Manufacturing Enterprises in Libya: A Stochastic Frontier Analysis
}

\author{
Hodud Essmui, Madeline Berma, Faridah Bt. Shahadan, Shamshubarida Bt. Ramlee \\ Faculty of Economics and Business, University Kebangsaan Malaysia \\ Correspondence: Hodud Essmui (email: hodudessmui@yahoo.com)
}

\begin{abstract}
This paper examines the performance of manufacturing firms in Libya. Specifically, it evaluates firm level technical efficiency. The paper uses an econometric approach based on a stochastic frontier production function to analyze 207 firms from survey conducted from March to May 2013. The results from estimations reveal that technical efficiencies of Libyan manufacturing firms ranging from 37.77 percent to 95.27 percent, with an average of 71.27 percent. While, the percent of firms that considered technically efficient is only 17.87 percent of the total firms.
\end{abstract}

Keywords: Manufacturing Industries, Technical Efficiency, Stochastic Frontier Analysis.

\section{Council for Innovative Research}

Peer Review Research Publishing System

Journal: International Journal of Management \& Information Technology

Vol. 5, No. 2

editor@cirworld.com

www.cirworld.com, member.cirworld.com 


\section{INTRODUCTION}

The manufacturing process may play a vital role in the development process by creating new jobs, increasing exports, and displacing imports. But efficiency is the first condition that has to be achieved to be competitive internationally. In order to accelerate the development process, industries have to become technically efficient (Batern, 2006). In the economically competitive world, good financial management is a key indicator of a corporation performance. The management of any company would like to identify and eliminate the underlying causes of inefficiencies, thus helping their firms to gain competitive advantage and attain sustainable competitive advantage, or at least, withstand the challenges from others (Haron, 2012).

Although, the manufacturing industry is an important sector to support the economic growth, little attention has been given to technical efficiency in the Libyan manufacturing firms when review of the literature on Libyan manufacturing sector. This sector is considered vital although it contributes about 6.3 percent to GDP in 2009 (Central Bank of Libya, 2011). The low contribution of the manufacturing sector in GDP may be the result of low-level of performance; hence this study seeks to analyze the technical efficiency of Libyan manufacturing firms to fill the gap in the literature relating to a study on Libyan manufacturing industry. The study applies a stochastic frontier production model to analyze the efficiency of the Libyan manufacturing firms.

This paper is structured as follows. The next section presents on overview of the manufacturing sector in Libya. Followed by, section three the literature review. Then the data, together with the methodology and econometric models for the estimation of technical efficiency will be discussed in section fourth. After that results from the analysis will be presented and discussed in the fifth section. The last section of the paper provides some concluding remarks and identifies several policy recommendations to improve the technical efficiency of manufacturing firms in Libya.

\section{OVERVIEW OF THE LIBYAN MANUFACTURING SECTOR}

Before the revolution in 1969, Libyan manufacturing industries concentrated primarily on processing domestic crops and livestock products and on handicraft products and 90 percent of Libya's manufacturing enterprises were located in Benghazi and Tripoli, and 75 to 80 percent of these were owned by Italians. Nearly 90 percent of the manufacturing enterprises were private, and most employed fewer than 20 workers. After 1969, the government adopted for a restricted industrial policy. In the late 1970s, the industrial sector (including manufacturing) was planned by the government, which had assumed control over those aspects of industrial production that were considered sensitive or too large for the domestic private sector. The new policy leaned heavily on freeing industry, including manufacturing, from dependence on foreign ownership or control, the government required local companies that engaged in trade to be Libyan and nationalized the properties of Italians, who represented the bulk of the country's entrepreneurship and private sector. Before 1980 the government concentrated on developing light processing and petrochemical industries. Processing of foodstuffs continued to remain a high priority, and the largest numbers of factories built during the 1970s were in this area. Other major manufacturing projects included textile complexes, a new oil refinery, two petrochemical plants, a fertilizer factory, and an electrical cable plant. During the period of high oil prices before 1981, the development of importdependent heavy industry seemed feasible. Libya enjoyed cheap energy costs in comparison to Europe and possessed the foreign exchange to pay for raw material imports. The 1980s decline in oil prices has reduced Libya's advantage in terms of energy costs and greatly cut into its supply of foreign exchange. This problem was obvious in existing industry during the mid 1980s, when production and productive capacity ratios for selected manufacturers varied substantially from year to year, depending on whether imported raw materials were available (Metz, 2004).

The pace of manufacturing growth sector in Libya is far behind of the oil and gas sector, where contribution of the manufacturing sector to the country's GDP did not exceed 10 percent over the whole period 1970-2009 as shown in Table (1). In the first sub period 1970-1979 the contribution of the manufacturing sector to gross domestic product (GDP) in Libya declined slightly from 2.2 percent in 1970 to 1.8 percent in 1975 . By the 1979 the share of manufacturing sector amounted to 2.4 percent of GDP. In absolute terms the value added by the sector increased from LD 65.5 million in 1970 to LD 185.8 million in 1979. However in current prices, value added increased at an average annual growth rate of 20.75 percent over the period 1970-1979. The value added of the manufacturing sector grew at an average rate of 9.04 percent throughout the period 1980-1989. Contribution of the manufacturing sector to gross domestic product (GDP) rose from 2 percent in 1980 to 5.4 percent in 1985. In absolute terms, the value added by the sector increased from LD 210.4 million in 1980 to LD 421.7 million in 1985. The share of manufacturing sector increased to 7.3 percent of GDP percent in 1988 before to declined to 6.7 percent of GDP in 1989. In the period 1990-1999 the value added of the manufacturing sector grew at an average rate of 5.24 per annum. The share of manufacturing sector increased from 7.1 percent of GDP in 1990 to 9.5 percent of GDP in 1993, the highest percentage achieved by manufacturing sector over the whole period. Then, the share of manufacturing sector fell to 7.2 percent of GDP in 1998. In the last sub period 2000-2009 value added of the manufacturing sector increased at an average annual growth rate of 20.75 percent over the period. In 2000 , the contribution of the manufacturing sector decreased from 5 percent of GDP to 4.6 percent of GDP in 2005. In contrast, the value added by the sector increased from LD 889.0 million in 2000 to LD 3124.8 million in 2005. By 2009 the contribution of this sector amounted to 6.3 percent of GDP, with value added accounted LD 5447.6 million.

Table 1. Structure of Libyan economy as \% of GDP 1970-2009

\begin{tabular}{|c|c|c|c|c|c|c|c|c|c|}
\hline Sector & $\mathbf{1 9 7 0}$ & $\mathbf{1 9 7 5}$ & $\mathbf{1 9 8 0}$ & $\mathbf{1 9 8 5}$ & $\mathbf{1 9 9 0}$ & $\mathbf{1 9 9 5}$ & $\mathbf{2 0 0 0}$ & $\mathbf{2 0 0 5}$ & $\mathbf{2 0 0 9}$ \\
\hline Agriculture & 2.6 & 2.3 & 2.2 & 4.4 & 6.2 & 9.5 & 8.1 & 2.2 & 2.8 \\
\hline Manufacturing & 2.2 & 1.8 & 2.0 & 5.4 & 7.1 & 8.2 & 5 & 4.7 & 6.3 \\
\hline Oil and gas & 63 & 53.4 & 61.8 & 44.6 & 35.0 & 24.9 & 39.8 & 66.1 & 54.6 \\
\hline
\end{tabular}

Source: GPC General Planning Council, Economic and Social Indicators, Various Issues.

GAI General Authority for Information, Statistics Book, Various Issues. 


\section{LITERATURE REVIEW}

This section identifies and describes the various approaches in the theoretical and empirical literature that are used to assess the efficiency of firms.

\subsection{Theoretical Literature}

Technical efficiency refers to the ability to minimize input use in the production of a given output vector, or the ability to obtain maximum output from given input vector (Kumbhakar and lovell 2000). The theoretical literature of technical efficiency has existed in the economic literature since Koopmans (1951), Debreu (1951) and Farrel (1957). According to Koopmans (1951) "A producer is technically efficient if an increase in an output requires a reduction in at least one other output or an increase in at least one input, and if a reduction in any input requires an increase in at least one other input or a reduction in at least one output". Subsequently, Debreu (1951) and Farrell (1957) defined the technical efficiency "one minus the maximum equiproportionate reduction in all inputs that still allows the production of given outputs, a value of one indicates technical efficiency and a score less than unity indicates the severity of technical inefficiency"(Porcell 2009). The measurement of technical efficiency empirically is dated back to Farrell (1957). Using linear programming techniques, Farrell provided a way to describe cost efficiency, and how to decompose cost efficiency into its technical and allocative, technical efficiency, which reflects the ability of a firm to obtain maximal output from a given set of inputs, and allocative efficiency, which reflects the ability of a firm to use the inputs in optimal proportions, given their respective prices and the production technology. These two measures are then combined to provide a measure of total economic efficiency (Coelli et al. 2005). Following these early theoretical and methodological on technical efficiency, many writers tried different techniques to estimate the production frontier and efficiencies. Essentially there are two main methodologies for measuring technical efficiency which have drawn wide attention from empirical researchers are the econometric (or parametric) approach, and the mathematical (or non-parametric) approach. Both approaches (parametric and nonparametric) are used in the assessment of productive efficiency with both cross section and panel data.

Data Envelopment Analysis (DEA) is a deterministic and nonparametric approach to efficiency measurement that has mostly been used in operational research and management science. Data Envelopment Analysis was initiated by the seminal work by Charnes, Cooper and Rhodes (1978) which had an input-oriented model with constant return to scale (CRS). This method which is currently known as basic DEA was an extension of "Farrell's measure to multiple - input multiple - output situations and operationalised it using mathematical programming" (Erkoc, 2012). Although, this technique does not require any prior assumptions about the functional relationship between inputs and output, a significant disadvantage of this procedure is that the computed inefficiency scores are very sensitive to measurement errors, either in output or the input variables (Soderbom, 2004). On the other hand, Stochastic Frontier Analysis (SFA), which was independently proposed by Aigner, Lovell, and Schmidt (1977) and Meeusen and Broeck (1977), has been a significant contribution to econometric modeling of production and the estimation of technical efficiency of firms. The stochastic frontier involved two random components, one associated with the presence of technical inefficiency and other being a traditional random error (Battese and Coelli, 1992). The advantages of this approach are that hypotheses can be tested with statistical rigour, and that relationships between inputs and outputs follow known functional forms. (Charoenrate, 2013).

\subsection{Empirical Studies}

There is growing studies that assess the technical efficiency of the manufacturing sector around the world. A number of studies have used a stochastic frontier analysis (SFA) to explore the technical efficiency of enterprises. Starting about ten years ago, Njikam (2003) assessed the effects of trade reform on firm specific technical efficiencies in Cameroon manufacturing by estimating a single stochastic production frontier for each industrial sector. The empirical results showed that the trade reform provided an enabling environment for improving firm-level technical efficiency, the average technical efficiency increased in six of eight sectors following trade reform. The post trade reform firm-level technical efficiencies increased on average at an annual rate of $1.39 \%$, while prior to trade reform they decreased on average at the annual rate of $0.76 \%$. Baten, et al. (2006) investigated the technical efficiency of manufacturing industries of Bangladesh, by using a stochastic frontier production function approach suggested by Battese and Coelli (1992). A feasible Cobb-Douglas stochastic frontier production function, which has time-varying technical inefficiency effects, was estimated. Two alternative distributions were used to model the random inefficiency term: a truncated normal distribution and a half-normal distribution. ). They found that the mean efficiencies according to the truncated and the half normal distributions are 40.22 percent and 55.57 percent respectively. Margono and Sharma (2006) estimated the technical efficiencies in food, textile, chemical and metal products industries from 1993 to 2000 in Indonesia. They also identified the determinants of technical efficiency of these industries, by using the stochastic frontier model. The results revealed that the food, textile, chemical and metal products sectors are on average 50.79 percent, 47.89 percent, 68.65 percent and 68.91 percent technically efficient, respectively. It is noted that ownership contributed to technical inefficiencies in the food sector; location and size contributed to technical inefficiencies in the textile sector, whereas size, ownership and age contributed to inefficiencies in the chemical and metal product industries. Ud Din et al. (2007) examined the efficiency of manufacturing sector of Pakistan for two periods 1995-1996 and 2000-2001. They adopted two competing techniques, the Stochastic Frontier Analysis (SFA), and the Data Envelopment Analysis (DEA). They found that there has been some improvement in the efficiency of the manufacturing sector, though the magnitude of improvement remains small. The mean efficiency score estimates using SFA increased from 0.58 in 1995-96 to 0.65 in 2000- 01. In terms of the DEA, the mean efficiency score improved from 0.23 in 1995-96 to 0.42 in 2000-01, indicating an improvement in efficiency of the large-scale manufacturing sector. Ajibefun (2007) analysed the technical efficiency of micro-enterprises in the Nigerian economy, 
using cross-sectional data collected from block-making, metal-fabricating and sawmilling enterprises in the three geographical regions (north, southwest and southeast regions) of Nigeria. Data collected were analysed using the stochastic frontier production functions. The results of the analysis show that the enterprises have varying level of technical efficiencies across enterprises, across scales of operation and across regions. Of the three geographical regions, both the least and the highest technical efficiencies come from micro-enterprises located in the southeastern regions of Nigeria. The mean technical efficiency ranges between 0.66 for sawmilling enterprises and 0.82 for metalfabricating enterprises. Radam et la. (2008) determine the technical efficiency of 7360 small and medium enterprises in Malaysia for the year 2004, using Stochastic Frontier Analysis (SFA). The results showed that the maximum estimated efficiency is 97.10 percent while the minimum is 0.30 percent, and the mean level of technical efficiency is 52.62 percent, while the number of firms considered technically efficient is only 3.06 percent of the total firms. Thus, in order to increase efficiency of the SMEs in Malaysia, policy makers have to play an important role in promoting economies of scale and developing technical skills of labors, which will lead to higher efficiency levels among SMEs. Asid (2010) estimated the technical efficiency for manufacturing industries in Malaysia for the periods of 1986 up to 1995, using the stochastic frontier model (SFM). The results showed that the technical efficiency for all sectors constantly increases at 0.01 percentage points each year. The most technically efficient industry was Industrial Chemicals with an average around 5.98 percent. The least efficient industry was Leather industries with an average is less than half percent. Le and Harvi (2010) examined the performance of domestic non-state manufacturing small and medium enterprises (SMEs) in Vietnam. Specifically, it evaluates firm level technical efficiency and identifies the determinants of technical efficiency of these SMEs, by using a stochastic frontier production function to analyse 5,204 observations of SMEs from three surveys conducted in 2002, 2005 and 2007. The results showed that manufacturing SMEs in Vietnam have relatively high average technical efficiency ranging from 84.2 percent to 92.5 percent. The study further examined the factors influencing efficiency. It finds that firm age, size, location, ownership, cooperation with a foreign partner, subcontracting, product innovation, competition, and government assistance are significantly related to technical efficiency. Exporting does not appear to influence technical efficiency. Radam, et al. (2012) investigate the technical efficiencies of rubber product manufacturing industry in Malaysia, using Stochastic Frontier Analysis (SFA). The study used secondary data from 313 firms that manufacture rubber product was obtained from the Annual Survey of Manufacturing Industries 2004 by Department of Statistics Malaysia. The results showed that the mean technical efficiency of manufactured rubber product industry in Malaysia is 70.33 percent. Majority of the firms are also fairly efficient in the use of available resources. Munongo and Chitungo (2013) investigated the technical efficiency in the Zimbabwean manufacturing industries using the stochastic frontier approach (SFA). The results indicated that there are varying efficiencies across sub-sectors and through time, the mean efficiency is 0.659 which indicates that on average an industry is 34.1 percent inefficient. The minimum efficiency is 0.135 and is in the textiles industry and the highest efficient industry operates at 99.1 percent efficiency and is the canning and preservation of vegetables and fruits industry. The study also showed that in the Zimbabwean manufacturing industries between 1980 and 2005 industries with strong the human capital development and foreign direct investment flows had higher efficiency. The concentration of foreign owned firms in an industry and capital intensity had no effect on the efficiency of an industry. Charoenrat et al. (2013) estimated technical efficiency of Thai manufacturing small and medium sized enterprises (SMEs), using a stochastic frontier analysis (SFA) and technical inefficiency effects model. The study used cross-sectional firm-level data from a 2007 census of Thai manufacturing SMEs. The empirical results indicated that their weighted average technical efficiency is approximately 50 percent, signifying a high level of technical inefficiency which is reducing potential output. The inefficiency effects model reveals that firm size, firm age, skilled labor, ownership characteristics and location are firm-specific factors that significantly affect the technical inefficiency of production. Ahmed and Ahmed (2013) estimate the technical efficiency of the seafood processing firms in Bangladesh by using stochastic frontier approach. They collected primary data about the firm's organizational and production processes through interviews and investigation of operational data. The results revealed that the industry runs on an average of 80 percent technical efficiency and has the potentials to increase productivity efficiency. The study also finds that the firms" age and size are the main sources of inefficiency. Smaller and newer firms are comparatively efficient than the larger and older ones.

In the context of Libyan's economy, empirical studies to measure technical efficiency on the manufacturing industry in Libya are limited. Kamaruddin \& Abokaresh (2012) is the study we could find in the literature on the efficiency of the Libyan manufacturing. Kamaruddin \& Abokaresh (2012) examined the technical efficiency of 21 Libyan manufacturing firms before and after privatization over the 2000 -2008 period, by using the Data Envelopment Analysis (DEA) technique. Their results indicated that the average efficiency score before privatization was 49.5 percent, but the score improved to 62.3 percent after privatization. The increase of 12.8 percent indicates that on average there is only minor improvement in technical efficiency of firms after privatization. Nevertheless, this increase was not statistically significant. Moreover, the results also indicated that even though there was an increase in technical efficiency scores of state (government) control and private owned firms, again this was not statistically significant. The present results suggest that firms in Libya are not prepared for the true sense of privatization, resulting in almost all firms facing difficulties in optimizing their own resources economically. Hence, efficiency is also not a function of ownership structure in the privatization context.

\section{METHODOLOGY}

\subsection{Model of Stochastic Frontier Production Function:}

The stochastic frontier production function was independently proposed by Aigner, Lovell and Schmidt (1977) and Meeusen and Van den Broeck (1977). The original specification involved a production function specified for crosssectional data which had an error term which had two components, one to account for random effects and another to account for technical inefficiency. This model can be expressed in the following form 


$$
Y_{i}=X_{i} \beta+\left(V_{i}-U_{i}\right) \quad, I=1, \ldots ., N,
$$

Where $Y_{i}$ is the production (or the logarithm of the production) of the i-th firm, $X_{i}$ is a $(1 \times \mathrm{K})$ vector of (transformation of the) input quantities of the $i$-th firm, $\beta$ is an vector of unknown parameters, $V i$ are random variables which are assumed to be iid. $\mathrm{N}\left(0, \delta^{2} \vee\right)$, Ui are non-negative unobservable random variables which are assumed to account for e technical inefficiency of production and are assumed to be iid. $\mathrm{N}\left(\mu_{\mathrm{i}}, \delta^{2} \mathrm{U}\right)$

Technical inefficiency effect model proposed by Battese and Coelli (1995) is described by

$$
\mu_{\text {it }}=Z_{\text {it }} \delta
$$

Where $Z_{i t}$ is a $p \times 1$ vector of variables which may influence the efficiency of firm, and $\delta$ is an $1 \times p$ vector of parameters to be estimated.

Battese and Coelli (1988) considered the maximum likelihood estimator which involves specification of the distribution of $V_{i}$ and $U_{i}$. The random variables $V_{i}$ and $U_{i}$ are assumed to be mutually independent and independent of the input variables in the model. If $U_{i}=0$, the assumed distribution is half-normal. Where outputs are expressed in logarithms, the technical efficiency of the $\mathrm{i}^{\text {th }}$ farm is estimated as a ratio of the observed to maximum feasible output, where the latter is provided by the stochastic frontier production. The measure of technical efficiency is given by

$$
\begin{aligned}
& T E_{i}=\exp \left(X_{i} \beta+v_{i}-\mu_{i}\right) / \exp \left(X_{i} \beta+v_{i}\right) \\
& T E_{i}=\exp \left(-\mu_{i}\right)
\end{aligned}
$$

If $U_{i}=0$, the firm were 100 percent efficient. Maximum-likelihood estimates of the parameters in the model are obtained using FRONTIER 4.1 which is developed by Coelli, 1994. The parametric model is estimated in terms of the variance parameters, $\delta^{2}{ }_{s}=\delta^{2}+\delta^{2}{ }_{v}$ and $y=\delta^{2} / \delta^{2}+\delta^{2}$ v. In case of cross-sectional data, the technical inefficiency model can only be estimated if the inefficiency effects $U_{i}$ 's are stochastic and have particular distributional properties (Battese and Coelli, 1995).

In our empirical study, we employ the stochastic frontier approach. The output of the manufacturing firms is assumed to be a function of three inputs, namely capital, material and labor. The form of the estimated stochastic frontier model in this study is represented by the Cobb-Douglas frontier model, which was defined as

$$
\ln Y_{i}=\beta_{0}+\beta_{1} \ln K_{i}+\beta_{2} \ln L_{i}+\beta_{3} \ln M_{i}+V_{i}+U_{i}
$$

where: $Y_{i}=$ output of firm $i, K_{i}=$ value of capital of firm $i, L_{i}=$ labour input of firm $i, M_{i}=$ value of materials for firm $i, V_{i}=$ random error in which $v_{i} N\left(0, \delta^{2} v\right), U_{i}=$ technical inefficiency in which $u_{i} N\left(\mu_{i}, \delta^{2} u\right)$,

\subsection{Data Collection}

The data for this study came from a detailed survey conducted in the months of March, April and May 2013 in Libya. The research instrument (semi-structured questionnaire) was designed by the author and captured information of output, labor, capital, materials and other firm specific variables. The questionnaire was administered to a sample of 377 firms by the author. Out of the 297 responses received only 207 were used for the production and efficiency tests. The responses that were excluded had incomplete data on production.

\section{EMPIRICAL RESULTS AND DISCUSSION}

The summary statistics related to the variables used for the analysis are depicted in Table (2). The number of employees ranged from 2 to 150 with a stander deviation of 21.445. The capital expenditure refers to the purchasing of assets, and the cost of alteration and major repair them, throughout the year. The average capital expenditure was almost LD1, 027,768.12 per year. The output refers to the value of output produced by a firm; the average output was LD 363608.70 . The materials measures all the materials used by an industry in the production in financial year. The average material was LD 2110707.73

The maximum likelihood estimated of the Cobb-Douglas stochastic frontier model with the assumption of half- normal is reproduced in Table (3) below for further discussion. The estimated ML coefficients for capital, materials and labour showed positive values of $0.0164,0.7848$ and 0.2019 respectively. The value of materials and labour were significant. This indicates that increment of the inputs, materials and labour by one per cent will increase output by 0.7848 per cent and 0.2019 per cent respectively. However, contrary to expectation, the coefficient for capital is not significant. The summation of the elasticities of the production function indicates the return to scale for MLE is 1.003 percent. In this case, a 1 percent increase in all inputs resulted in an increase of 1.003 percent in output level for stochastic frontier.

The MLE provide estimates of the variance parameters sigma - squared $\left(\delta^{2}\right)$ and gamma $(\gamma)$. The first variance parameter, $\delta^{2}$, determines whether there is technical inefficiency or not. If $\delta^{2}$ is equal to zero, all firms are fully efficient. If $\delta^{2}$ is larger than zero, then all firms are not fully efficient. Table (3) shows that the value of $\delta^{2}$ is 0.3498 , indicating that all firms in the sample are not fully efficient, In addition, the estimated variance $\delta^{2}$ is statistically significant at 1 percent, indicating goodness of fit and correctness of the specified distribution assumptions of the composite error term. The second variance parameter, $\gamma$, determines whether all deviations from the frontier are due to random error or technical inefficiency. If $y$ is equal to zero then all deviations from the frontier are caused by random error. If $y$ is equal to one, then all deviations from the frontier are caused by technical inefficiency. Gamma ( $\mathrm{Y}$ ) is estimated at 0.9173 and is statistically 
significant at 1 percent indicating that over 92 percent of the total variation from the frontier is due to technical inefficiency. The result also reveals that $\mathrm{TE}=0.71$ percent indicating the presence of inefficiency to the extent of 29 percent.

Table 2. Descriptive results: Summary statistics for variables in the stochastic frontier production function

\begin{tabular}{|c|c|c|c|c|}
\hline Variables & Mean & Minimum & Maximum & Std - deviation \\
\hline Output & 363608.70 & 15000 & 11000000 & 980410.562 \\
\hline Capital & 1027768.12 & 6000 & 68000000 & 5147492.946 \\
\hline Materials & 2110707.73 & 5000 & 4000000 & 27793159.527 \\
\hline Labour & 15.56 & 2 & 150 & 21.445 \\
\hline
\end{tabular}

Table 3. Maximum Likelihood estimates of the Stochastic Frontier Production

\begin{tabular}{|c|c|c|c|c|}
\hline Variables & Parameters & Coefficients & $\begin{array}{l}\text { Standard } \\
\text { deviation }\end{array}$ & t-ratio \\
\hline Constant & $\beta_{0}$ & 0.2842 & 0.3003 & $9.4629^{*}$ \\
\hline Ln(Capital) & $\beta_{1}$ & 0.0164 & 0.0190 & 0.8621 \\
\hline Ln(Materials) & $\beta_{2}$ & 0.7848 & 0.0319 & $24.5314^{*}$ \\
\hline Ln(Labour) & $\beta_{3}$ & 0.2019 & 0.0357 & $5.6592^{*}$ \\
\hline \multicolumn{5}{|l|}{ Variance parameters } \\
\hline Sigma - squared & $\delta^{2}$ & 0.3498 & 0.0434 & $8.0641^{*}$ \\
\hline Gamma & $\mathrm{Y}$ & 0.9173 & 0.0291 & $31.5032^{*}$ \\
\hline \multicolumn{5}{|l|}{ Log liklhood function } \\
\hline LR-Test & & 69.1365 & & \\
\hline Mean TE & & 0.7127 & & \\
\hline רors' & & & & \\
\hline
\end{tabular}

The technical efficiency indexes using Jondorow et al., (1982) procedure are presented in Table (4) based on the estimated of the frontier function. The mean technical efficiency for manufacturing enterprises is estimated at 71.27 percent. This result indicates that manufacturing firms in Libya can increase the current level of output by 28.73 percent with same level of output. Compared to the mean technical efficiency at around 60 percent to 70 percent of the best practice frontier in developing countries, as reported by Tybout (2000), Libyan manufacturing enterprises are quite efficient. The study reveals technical efficiency (TE) of Libyan manufacturing enterprises ranging from 37.77 percent to 95.27 percent, with an average of 71.27 percent. In addition, the highest TE level ranging from 60 percent to 69.99 percent comprises 77 firms, which is 37.20 percent of the total. The lowest TE score from 30 percent to 39.99 percent comprises 1 firm, or 0.48 percent. According to Grabowski et al., (1990), a firm is considered technically inefficient even if the firm registered a technical efficiency index of 82 percent. By this standard, the number of firms considered technically efficient is only 17.87 percent of total firms.

Table 4. Distribution of technical efficiencies (based on Cobb-Douglas specification)

\begin{tabular}{|c|c|c|}
\hline TE level (\%) & No. of firms & Percent (\%) \\
\hline Less than $10 \%$ & 0 & 0 \\
\hline $10.00-19.99 \%$ & 0 & 0 \\
\hline $20.00-29.99 \%$ & 0 & 0.48 \\
\hline $30.00-39.99 \%$ & 4 & 1.93 \\
\hline $40.00-49.99 \%$ & 13 & 6.28 \\
\hline $50.00-59.99 \%$ & 77 & 37.20 \\
\hline $60.00-69.99 \%$ & 70 & 33.82 \\
\hline $70.00-79.99 \%$ & 35 & 16.91 \\
\hline $80.00-89.99 \%$ & 13 & 0 \\
\hline
\end{tabular}




\begin{tabular}{|c|c|c|}
\hline $90.00-99.99 \%$ & 7 & 3.38 \\
\hline Total & $\mathbf{2 0 7}$ & $\mathbf{1 0 0}$ \\
\hline Mean TE (\%) & \multicolumn{2}{|c|}{71.27} \\
\hline Minimum TE (\%) & 37.77 \\
\hline Maximum TE (\%) & \multicolumn{2}{|c|}{95.27} \\
\hline
\end{tabular}

\section{CONCLUSION}

The aim of this study was to give a measure of the level of inefficiency in the manufacturing enterprises in Libya. The paper used a stochastic frontier model, employing cross sectional data covering randomly sampled 207 manufacturing firms in Libya. The results obtained from the stochastic frontier estimation show that the mean efficiency is 71.27 percent which indicates that on average an industry 28.73 percent inefficient. Thus there can be an increase in the output without increasing the input by 28.37 percent. The minimum efficiency is 37.77 percent and the maximum efficiency is 95.27 percent. While, the percent of firms that considered technically efficient is only 17.87 percent of the total firms. To further improve the operation of these manufacturing enterprises, government should be provided some technical assistance like training programs for the owner to improve management skills to enhance efficient use of manufacturing resources to help the least efficient enterprises to increase efficient utilization of resources and improve the national output. These efforts will improve the efficiency of manufacturing industry in this country.

\section{REFERENCES}

[1] Ahmed, M.S and Ahmed, M.D. (2013). Efficiency Variation of Manufacturing Firms: A Case Study of Seafood Processing Firms in Bangladesh. Review of Economics \& Finance. ISSNs: 1923-7529; 1923-8401 (C) 2013 Academic Research Centre of Canada.

[2] Aigner DJ, Lovell, C.A.K., and Schmidt, P.J. (1977). Formulation and estimation of stochastic frontier production function models. Journal of Econometrics 6(1):21-37

[3] Ajibefun, I.A. (2007). Technical Efficiency Analysis of Micro-enterprises: Theoretical and Methodological Approach of the Stochastic Frontier Production Functions Applied to Nigerian Data. Journal of African Economies 1: 1-46.

[4] Asid, R. (2010). The Technical Efficiency Analyses of Manufacturing Sector in Malaysia: Evidence from the First Industrial Master Plan (1986-1995). Asian Social Science, Vol.6, No.2

[5] Battese, G. E. and Coelli, T.J. (1988). Prediction of firm-level technical efficiencies with a generalized frontier production function and panel data. Journal of Econometrics, 38: 387-399.

[6] Battese, G.E. and Coelli, T.J. (1992). 'Frontier Production Functions, Technical Efficiency and Panel Data: With Application to Paddy Farmers in India', Journal of Productivity Analysis, 3: 153-169.

[7] Battese, G. E. and Coelli. T.J. (1995). A model for technical inefficiency effects in a stochastic frontier production function for panel data. Empirical Economics, 20, 325-332.

[8] Baten, M. A, Rana, M., Das, S and Khaleque, M.A. (2006). Technical Efficiency of Some Selected Manufacturing Industries in Bangladesh: A Stochastic Frontier Analysis. The Lahore Journal of Economics $11: 2$ (Winter 2006) pp. 23-41

[9] Charoenrat, T. ,Harvie, C. and Amornkitvikai, Y. (2013). Thai manufacturing small and medium sized enterprise technical efficiency: Evidence from firm-level industrial census data. Journal of Asian Economics 27: 42-56.

[10] Coelli, T. J. (1996). A guide to FRONTIER version 4.1: A computer program for stochastic frontier production and cost function estimation. CEPA Working Papers, No. 7/96, ISBN 186389 4950, Department of Econometrics, University of New England, Armidale, pp. 33.

[11] Coelli, T.J., Rao, D.S.P., O'Donnell, C.J.and Battese, G.E. (2005). An Introduction to Efficiency and Productivity Analysis. New York: Springer.

[12] Debru, G. (1951). 'The Coefficient of Resource Utilization', Econometrica, 19: 273-292.

[13] Erkoc, T.E. (2012). Estimation Methodology of Economic Efficiency: Stochastic Frontier Analysis vs Data Envelopment Analysis. International Journal of Academic Research in Economics and Management Sciences 1(1).

[14] Farrell, M.J., 1957, 'The Measurement of Productive Efficiency', Journal of the Royal Statistical Society, Series A, 120: 253-290.

[15] Grabowski, R, Kraft, S. Pasurka, C. and Hassan. A. (1990). A Ray-Homothenic and Efficiency: Grain Farms in Southern Illinois. Eroupean Review Agricultural Economics, 17, 435- 448.

[16] GPC General Planning Council, Economic and Social Indicators, Various Issues.

[17] GAI General Information Authority, Statistics Book, Various Issues. 
[18] Jondrow, J., Lovell, C. A. K., Materov, I. S. and Schmidt, P. (1982). On Estimation of Technical Inefficiency in the Stochastic Frontier Production Function Model. Journal of Econometrics, 19 (2/3), 233-238.

[19] Kamaruddin, H.B. and Abokaresh, M.S.M. (2012). The Performance of Privatized Firms: Empirical Analysis for Libya. International Review of Business Research Papers.Vol. 8. No.6: 134.

[20] Kumbhakar, S. and Lovell, C. A. K (2003). Stochastic Frontier Analysis. Cambridge U.K.: Cambridge University Press.

[21] Koopmans, T.C. (1951). 'An Analysis of Production as an Efficient Combination of Activities', in T.C. Koopmans, Ed., Activity Analysis of Production and Allocation, Cowles Commission for Research in Economics, Monograph No.13, Wiley, New York.

[22] Le, V.,and Harvie,C. (2010). Firm performance in Vietnam: Evidence from manufacturing small and medium enterprises. University of Wollongong Economics, Working Paper Series 04-10.

[23] Margono, H and Sharma, S. (2006). Efficiency and productivity analyses of Indonesian manufacturing industries. Journal of Asian Economics 17: 979-995.

[24] Meeusen, W and van den Broeck, J .(1977). Efficiency estimation from Cobb-Douglas production functions with composed error. International Economic Review 18:435-444.

[25] Metz, H.C.(2004). Libya. Kessinger Publishing.

[26] Munongo, S. and Chitungo, S.K. (2013). Determinants of technical efficiency in the Zimbabwean manufacturing industries. International Journal of Management \& Information Technology Volume 3, No 1, January, 2013. ISSN: 2278-5612

[27] Njikam, O.(2003). Trade Reform and Efficiency in Cameroon's Manufacturing industries. African Economic Research Consortium, Nairobi. (AERC Research Paper 133.)

[28] Porcelli, F. (2009).Measurement of Technical Efficiency: A brief survey on parametric and non-parametric techniques. http://www2.warwick.ac.uk/fac/soc/economics/staff/phd students/porcelli/porcelli dea sfm.pdf

[29] Radam, A., Ahali, N.M. and Baharom, H. A. (2012). Technical efficiency of manufactured rubber product in Malaysia: stochastic frontier analysis. Production Management, 42: 6466-6471.

[30] Radam, A., Abu, M. and Abdullah, A.M. (2008). Technical Efficiency of Small and Medium Enterprise in Malaysia: A Stochastic Frontier Production Model. Journal of Economics and Management 2(2): 395 - 408.

[31] Soderbom, M \&, Teal, F. (2004). Size and efficiency in African manufacturing firms: evidence from firm-level panel data. Journal of Development Economics 73: 369- 394.

[32] Ud Din, M., Ghani, E. and Mahmood, T. (2007). Technical Efficiency of Pakistan's Manufacturing Sector: A Stochastic Frontier and Data Envelopment Analysis. The Pakistan Development Review 46: 1 (Spring 2007) pp. 1-18 